\title{
Computed Tomography Assisted Biopsy
}

National Cancer Institute

\section{Source}

National Cancer Institute. Computed Tomography Assisted Biopsy. NCI Thesaurus. Code C137909.

Biopsy of tissue using computed tomography as an aid in directing a biopsy needle into the area of interest. 